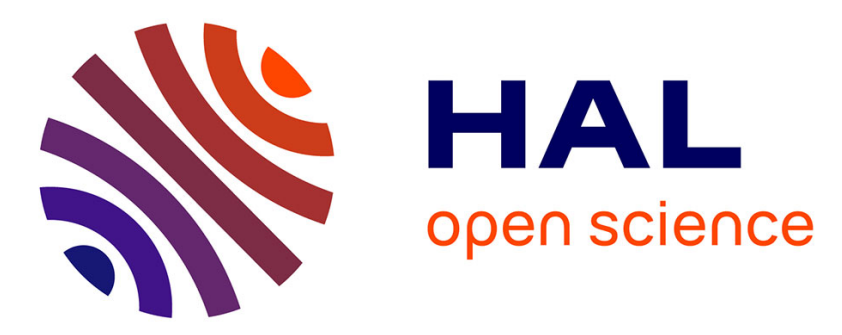

\title{
Bearing Fault Detection in DFIG-Based Wind Turbines Using the First Intrinsic Mode Function
}

Yassine Amirat, Vincent V. Choqueuse, Mohamed Benbouzid, Jean-Frederic

Charpentier

\section{- To cite this version:}

Yassine Amirat, Vincent V. Choqueuse, Mohamed Benbouzid, Jean-Frederic Charpentier. Bearing Fault Detection in DFIG-Based Wind Turbines Using the First Intrinsic Mode Function. XIX International Conference on Electrical Machines - ICEM 2010, Rome, Sep 2010, Rome, Italy. pp.1 - 6, 10.1109/ICELMACH.2010.5608066 . hal-00531190

\author{
HAL Id: hal-00531190 \\ https://hal.science/hal-00531190
}

Submitted on 2 Nov 2010

HAL is a multi-disciplinary open access archive for the deposit and dissemination of scientific research documents, whether they are published or not. The documents may come from teaching and research institutions in France or abroad, or from public or private research centers.
L'archive ouverte pluridisciplinaire HAL, est destinée au dépôt et à la diffusion de documents scientifiques de niveau recherche, publiés ou non, émanant des établissements d'enseignement et de recherche français ou étrangers, des laboratoires publics ou privés. 


\title{
Bearing Fault Detection in DFIG-Based Wind Turbines Using the First Intrinsic Mode Function
}

\author{
Y. Amirat, V. Choqueuse, M.E.H. Benbouzid and J.F. Charpentier
}

\begin{abstract}
Wind energy conversion systems have become a focal point in the research of renewable energy sources. In order to make the DFIG-based wind turbines so competitive as the classical electric power stations it is important to reduce the operational and maintenance costs by continuously monitoring the condition of these systems. This paper provides a method for bearing fault detection in DFIG-based wind turbines. The proposed method uses the first Intrinsic Mode Function (IMF) of the stator current signal. After extracting the first IMF, amplitude-demodulation is performed to reveal a generator bearing fault. Experimental results show that the proposed method significantly improves the result of classical amplitudedemodulation techniques for failure detection.
\end{abstract}

Index Terms-Wind turbine, Doubly Fed Induction Generator (DFIG), fault detection, bearings, signal processing

\section{INTRODUCTION}

Wind energy conversion systems is the fastest-growing source of new electric generation in the world and it is expected to remain so for some time. In order to be more reliable and competitive than classical power generation systems and due to geographical location of DFIG-based wind turbines, it is important to prevent failure and to reduce maintenance cost. A deep knowledge about all the phenomena involved during the occurrence of a failure constitutes an essential background for the development of any failure diagnostic system. Regarding a failure as a particular input acting on the generator, a diagnostic system must be able to detect its occurrence, as well as to isolate it from all other inputs such as disturbances and controls affecting the behavior of the DFIG. For the failure detection problem, we would like to know if a failure exists or not in the Wind energy conversion system via the processing of available measurements.

A quantitative analysis of real wind turbine failure data has shown important features of failure rate values and trends [1] [3]. A failures number distribution check-off is reported in Fig. 1 for Swedish wind power plants that occurred between 2000 and 2004 [3]. This figure shows that $45 \%$ of failures were linked to the electrical system, sensors and blades/pitch components. Experience feedback of wind turbine industries

Y. Amirat, V. Choqueuse and M.E.H Benbouzid are with the University of Brest, laboratory LBMS, EA 4325, Rue de Kergoat, CS 93837 , 29238 Brest Cedex 03, FRANCE. e-mail: yassine.amirat@univ-brest.fr, vincent.choqueuse@gmail.com, mohamed.benbouzid@univ-brest.fr. J.F. Charpentier is with the French Naval Academy Research Institute (IRENav EA 3634), French Naval Academy, Lanveoc-Poulmic, CC 600, 29240 Brest Cedex 9, France (e-mail: jean-frederic.charpentier@ecole-navale.fr).

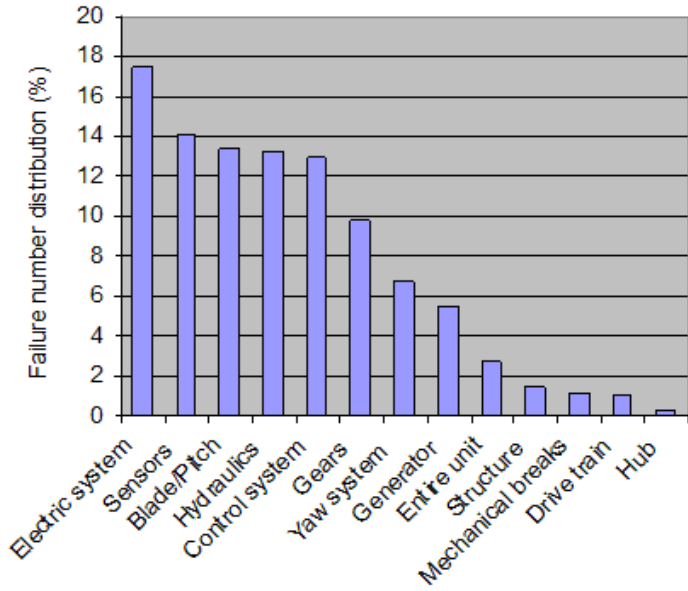

Fig. 1. Failures number distribution for Swedish wind power plants between 2000-2004 [3].

corroborates that the major concern is on the electrical system. Typical failures include:

- Generator bearing failure

- Dynamic air-gap irregularities

- Stator and rotor winding insulation failures.

- Inter-turn short circuits in stator windings

- Broken rotor bar or cracked rotor end-rings

- Harmonic derating

Many methods are available for condition monitoring of DFIG-based wind turbines. These include electrical quantities signature analysis (current, power,...), vibration monitoring, temperature monitoring and oil monitoring. In the case of DFIG-based wind turbines, it has been shown that failure in the drive train could be diagnosed from the electrical quantities of the generator. This principle has been used to diagnose unbalance and failure in the blades of a small wind turbine by measuring the power spectrum density at the turbine generator terminals [4]. The advantage of electrical signature analysis over other monitoring techniques is that the signals are easily accessible during operation i.e. the current can be acquired by current transformer, the voltage via a voltage transformer and the power by computation. Moreover, current and voltage transducers are usually cheaper than vibration and torque transducers. In this paper, the generator current is employed to detect faults in wind turbines. From a decision point of view, failure detection based on the current signal usually involves two steps: 1) a preprocessing step and a 2) failure detection 


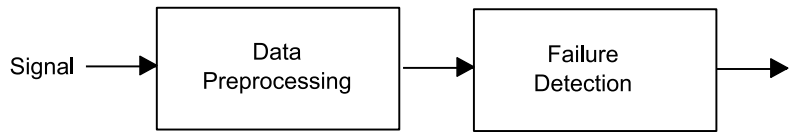

Fig. 2. Fault detection framework.

step (see Fig.2). The aim of the preprocessing step is to project the signal into a new space in order to facilitate the failure detection. In the literature, many preprocessing techniques have been proposed. These include the popular Fast Fourier Transform (FFT) [5], time-frequency representations [6]-[8], time-scale decompositions [9]-[11] and AM/FM demodulation techniques [12]-[16]. The major drawback of FFT and timefrequency representations is that they require the knowledge of the frequency components affected by the generator failure. Similarly, analysis based on wavelet decomposition usually requires the knowledge of the scale associated with the failure. Another commonly used method is the AM/FM demodulation technique. AM/FM demodulation technique is a well-suited tool for data preprocessing since most of the machine failure leads to current modulation [7], [8]. Under the assumption of a mono-component signal (i.e. $x(n)=a(n) \cos (\phi(n))$ ), classical demodulation approaches are the Hilbert transform [13], [14] and the Teager energy operator [15], [16]. Unfortunately, in practice, both of these approaches are inappropriate as the mono-component assumption is rarely satisfied. To satisfy this assumption, band-pass filtering can be employed, however, it requires the knowledge of the central band-pass frequency and a proper filter design.

In this paper, we propose to use an Empirical Mode Decomposition (EMD) [17] to automatically extract a monocomponent signal, called Intrinsic Mode Function (IMF), from the stator current signal. Then, we employ an Hilbert transform for AM demodulation. As opposed to the Hilbert-Huang transform which has been previously used for failure detection [18], [19], we propose to exploit only the first IMF since it contains most of the useful information. This paper is organized as follows. Section II presents the proposed approach and Section III reports on the experimental results.

\section{PReprocessing BASED ON The First IMF AND AM DEMODULATION}

Let us denote by $x(n)(n=1, \cdots, N)$ the stator current signal. Under the multi-component assumption, $x(n)$ can be decomposed as

$$
x(n)=\sum_{k=1}^{n} \underbrace{a_{k}(n) \cos \left(\phi_{k}(n)\right)}_{\operatorname{IMF}_{k}(n)}+r(n)
$$

where $\operatorname{IMF}_{k}(n)$ is the $k^{t h}$ Intrinsic Mode Function (IMF) and $r(n)$ is the residue. In practice, the IMFs are unknown and must be extracted from the stator current signal $x(n)$.

\section{A. Extraction of the First IMF}

The IMFs and the residue can be extracted from $x(n)$ by using an Empirical Mode Decomposition (EMD) [17]. This decomposition can be described as follows:

1) Identification of all extrema of $x(n)$

2) Interpolation between minimal (resp. maxima) ending up with some envelope $e_{\min }(n)$ (resp. $e_{\max }(n)$ ).

3) computation of the mean:

$$
r(n)=\frac{e_{\min }(n)+e_{\max }(n)}{2}
$$

4) extraction of the detail:

$$
\mathrm{IMF}_{k}(n)=x(n)-r(n)
$$

5) Iteration on the residue $r(n)$.

In practice, this algorithm has to be refined by a shifting process until the detail $\operatorname{IMF}_{k}(n)$ can be considered as an Intrinsic Mode Function [20]. In the following, we only decompose the stator current signal into one IMF and a residue $(k=1)$ since this decomposition concentrates most of the useful information about the failure into one IMF. Increasing the number of components $k$ tends to spread the information about the failure through several IMFs which can render interpretation more difficult.

Figures 3 to 6 present the current $x(n)$, the first IMF $\mathrm{IMF}_{1}(n)$ and the residue $r(n)$ after one iteration of the EMD algorithm for healthy and faulty generators. For healthy generators (Figs. 3 and 5), one can notice that the first IMF is close to 0 and that the signal $x(n)$ is close the residue $r(n)$. On the contrary, for faulty generators, Figs. 4 and 6 show that the first IMF is no longer equal to 0 . This behavior can be observed for faulty generators with bearing inner race deterioration (Fig. 4) and with bearing ball deterioration (Fig. 6).

\section{B. Amplitude Demodulation}

After applying the EMD, the first IMF is a mono-component signal which can be further processed with a classical demodulation tool. Indeed using (1), the first IMF, $y(n)$, can be expressed as

$$
y(n)=\operatorname{IMF}_{1}(n)=a_{1}(n) \cos \left(\phi_{1}(n)\right)
$$

Under the assumption that a failure leads to stator amplitude modulation, most of the useful information is contained in the amplitude envelope $\left|a_{1}(n)\right|$. To extract $\left|a_{1}(n)\right|$ from $y(n)$, we propose to use an amplitude demodulation technique based on the Discrete Hilbert transform (DHT). The DHT of $y(n)$ is given by [21]

$$
\mathcal{H}[y(n)]=\mathcal{F}^{-1}\{\mathcal{F}\{y(n)\} \cdot u(n)\}
$$

where $\mathcal{F}\{$.$\} and \mathcal{F}^{-1}\{$.$\} correspond to the Fast Fourier$ Transform (FFT) and Inverse FFT (IFFT), respectively, and where $u(n)$ is defined as:

$$
u(n)= \begin{cases}1, & n=0, \frac{N}{2} \\ 2, & n=1,2, \ldots, \frac{N}{2}-1 \\ 0, & n=\frac{N}{2}-1, \cdots, N-1\end{cases}
$$



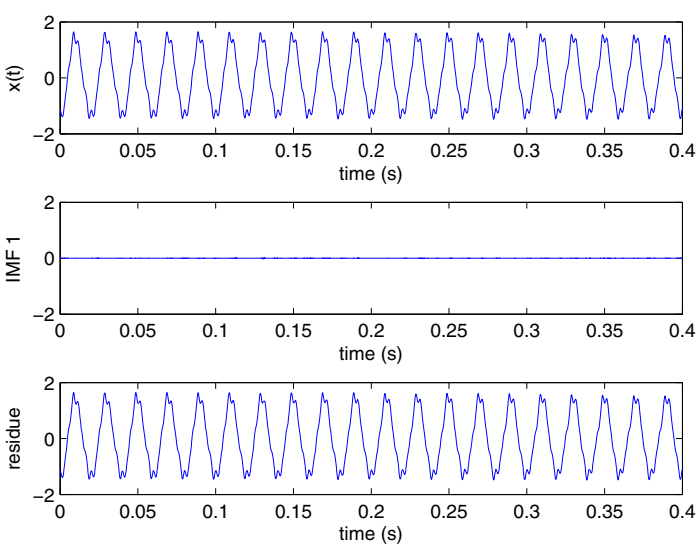

Fig. 3. EMD: Healthy generator (load 100W)
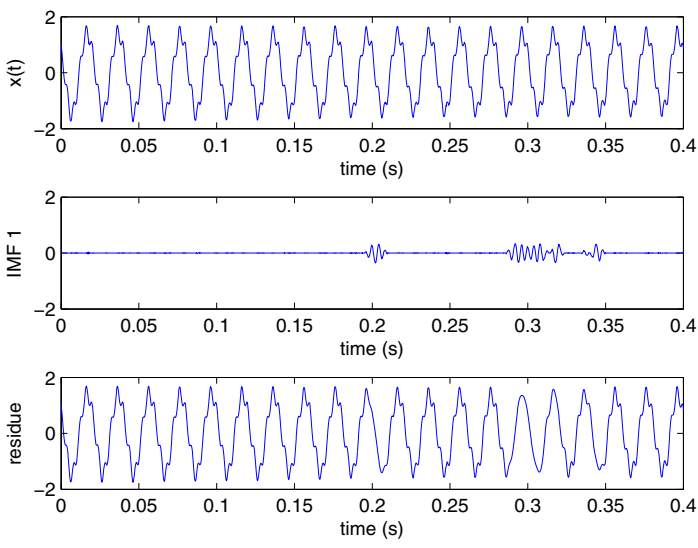

Fig. 4. EMD: Bearing inner race deterioration (load 100W).

The estimated envelope, denoted $\left|\widehat{a}_{1}(n)\right|$, is then given by [21]

$$
\left|\widehat{a}_{1}(n)\right|=\sqrt{y^{2}(n)+(\mathcal{H}[y(n)])^{2}}
$$

Figures 7 to 10 display the amplitude envelope $\left|\widehat{a}_{1}(n)\right|$ for healthy and faulty generators. For healthy generators in Figs. 7 and 9 , one can notice that the envelopes are close to 0 and do not exhibit strong variation. On the contrary, for faulty generators in Figs. 8 and 10, one can observe that the amplitude envelopes is no longer equal to 0 and exhibit much more variation.

\section{Failure Detection Criterion}

In this section, we propose a simple criterion to distinguish between healthy and faulty generators. Let us consider the mono-component signal $y(n)$ in (4). Without any failure, there is no amplitude modulation and so $\left|\widehat{a}_{1}(n)\right|$ is approximatively constant. When a failure occurs, the envelope $\left|\widehat{a}_{1}(n)\right|$ is no longer constant and exhibits variation. One measure of the amount of variation is the variance which is defined as

$$
\sigma^{2}=\frac{1}{N} \sum_{n=0}^{N-1}\left(\left|\widehat{a}_{1}(n)\right|-\mu\right)^{2}
$$
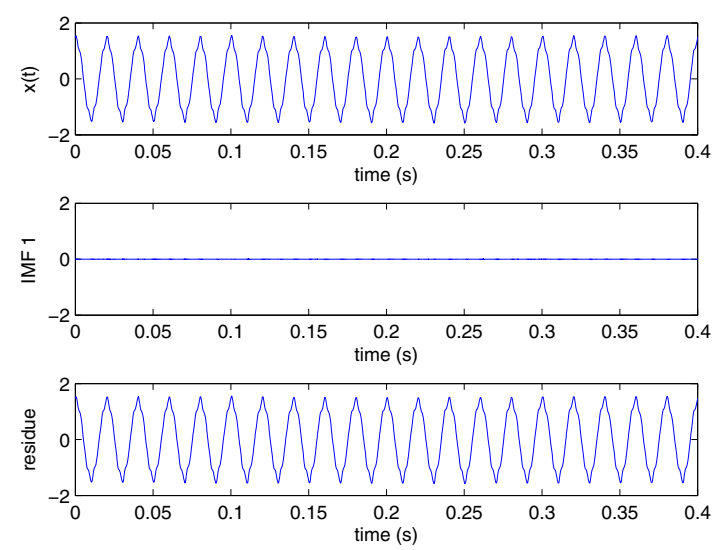

Fig. 5. EMD: Healthy generator (load 300W)
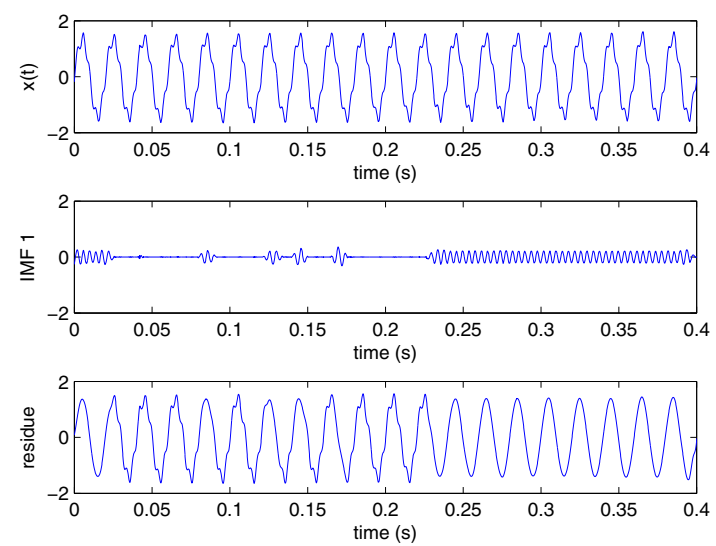

Fig. 6. EMD: Bearing ball deterioration (load 300W).

where $\mu$ is the average of $\left|\widehat{a}_{1}(n)\right|$, i.e.

$$
\mu=\frac{1}{N} \sum_{n=0}^{N-1}\left|\widehat{a}_{1}(n)\right|
$$

For healthy generator, $\left|\widehat{a}_{1}(n)\right|$ is supposed to be constant and so $\sigma^{2}=0$. On the contrary, for faulty generators, $\left|\widehat{a}_{1}(n)\right|$ exhibits variation and so $\sigma^{2}>0$. Therefore, the value of the statistical criterion $\sigma^{2}$ can be used to distinguish between healthy and faulty generators. One should note that the coefficient $N$ determines the compromise between robustness and reactivity of the criterion $\sigma^{2}$. Indeed, for a large $N, \sigma^{2}$ is less sensible to noise but it requires to analyse more data, which can increase latency of the diagnosis system.

\section{EXPERIMENTAL RESULTS}

In this section, the result of the proposed approach is presented with experimental signals. Figure 11 describes the experimental setup that is operated in the motor configuration for experimental easiness. It is composed of two parts: a mechanical part that has a tacho-generator, a three-phase induction motor and an alternator. The tacho-generator is a 


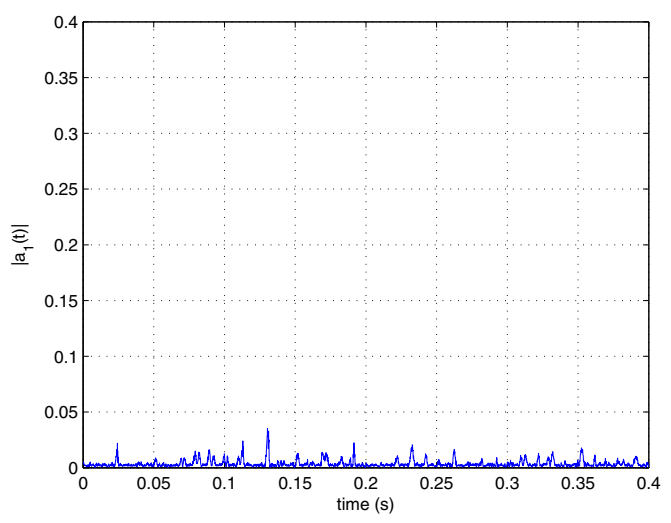

Fig. 7. AM demodulation: Healthy generator (load 100W).

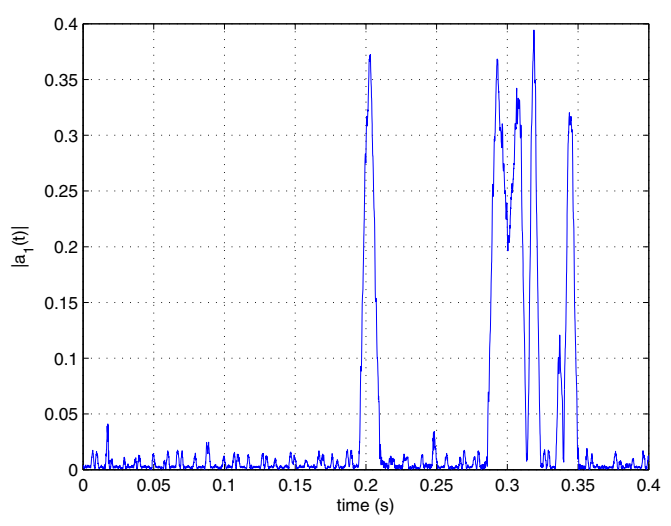

Fig. 8. AM demodulation: Bearing inner race deterioration (load 100W).

DC machine that generates $90 \mathrm{~V}$ at $3000 \mathrm{rpm}$. It is used to measure the speed. It produces linear voltage between 2500 and $3000 \mathrm{rpm}$. The alternator is a three-phase synchronous machine with a regulator and a rectifier circuit that stabilize the output voltage at $12 \mathrm{VDC}$. The advantage of using a car alternator instead of DC generator is obtaining constant output voltage at various speeds. The induction motor could be identically loaded at different speeds. Moreover, if the induction motor is supplied from the network, motor current will have time harmonic components as well as bearing fault harmonics. This makes it harder to determine the bearing failure effect on the stator current and therefore complicates the fault detection process. For these reasons, the induction motor is fed by an alternator. By this way, supply harmonics effects are eliminated and only bearing failure effects could be observed on the stator current.

The tested induction motor has the following rated parameters: $0.75 \mathrm{~kW}, 220 / 380 \mathrm{~V}, 1.95 / 3.4 \mathrm{~A}, 2780 \mathrm{rpm}, 50 \mathrm{~Hz}, 2$ poles, Y-connected. It has two 6204.2ZR type bearings. From the bearing data sheet the following parameters are obtained: The outside diameter is $47 \mathrm{~mm}$ and inside one is $20 \mathrm{~mm}$. Assuming that the inner and the outer races have the same thickness gives the pitch diameter $D_{P}=31.85 \mathrm{~mm}$. The bearing has eight balls $(N=8)$ with an approximate diameter of $D_{B}=12 \mathrm{~mm}$

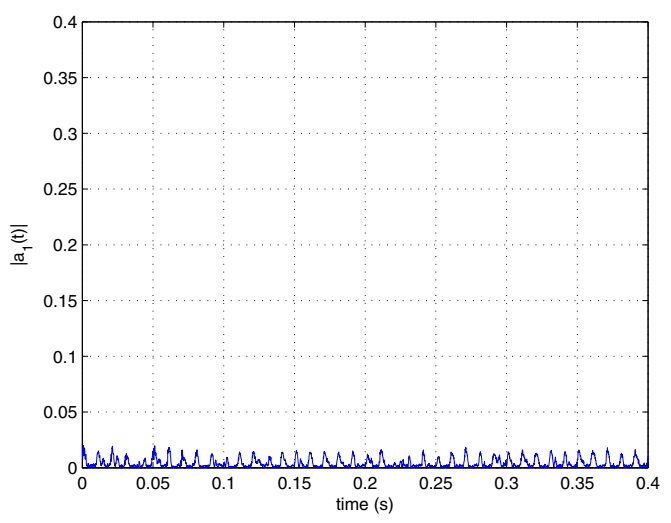

Fig. 9. AM demodulation: Healthy generator (load 300W).

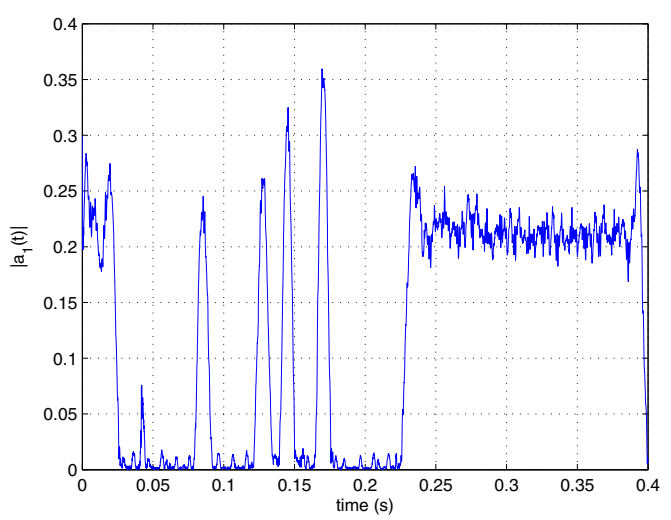

Fig. 10. AM demodulation: Bearing ball deterioration (load 300W).

TABLE I

VALUES OF THE PROPOSED CRITERION $\sigma^{2}$ FOR HEALTHY AND FAULTY GENERATORS (LOAD $100 \mathrm{~W}$ ).

\begin{tabular}{|l|c|c|}
\hline Generator & $x(n)$ & $y(n)=\mathrm{IMF}_{1}(n)$ \\
\hline Healthy generator & $\sigma^{2}=0.02527$ & $\sigma^{2}=0.00020$ \\
Inner race deterioration & $\sigma^{2}=0.05036$ & $\sigma^{2}=0.00766$ \\
Cage deterioration & $\sigma^{2}=0.05840$ & $\sigma^{2}=0.01156$ \\
Ball deterioration & $\sigma^{2}=0.05517$ & $\sigma^{2}=0.00933$ \\
\hline
\end{tabular}

TABLE II

VALUES OF THE PROPOSED CRITERION $\sigma^{2}$ FOR HEALTHY AND FAULTY GENERATORS (LOAD $200 \mathrm{~W}$ ).

\begin{tabular}{|l|c|c|}
\hline Generator Signal & $x(n)$ & $y(n)=\mathrm{IMF}_{1}(n)$ \\
\hline Healthy generator & $\sigma^{2}=0.01953$ & $\sigma^{2}=0.00012$ \\
Inner race deterioration & $\sigma^{2}=0.03893$ & $\sigma^{2}=0.00642$ \\
Cage deterioration & $\sigma^{2}=0.04627$ & $\sigma^{2}=0.00231$ \\
Ball deterioration & $\sigma^{2}=0.04652$ & $\sigma^{2}=0.01138$ \\
\hline
\end{tabular}

and a contact angle $\theta=0^{\circ}$. These bearings are made to fail by drilling holes of various radiuses with a diamond twist bit while controlling temperature by oil circulation in experiments. Some of the artificially deteriorated bearings are shown in Fig. 12.

Tables I, II and III present the value of the failure detection 


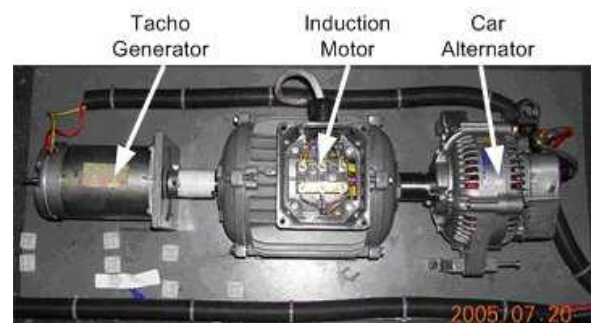

Mechanical Part of

Experimental setup

Connectors to the Current
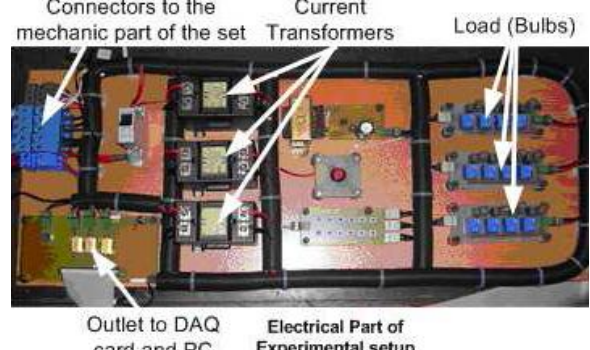

card and PC Experimental setup

Fig. 11. Experimental setup [22].

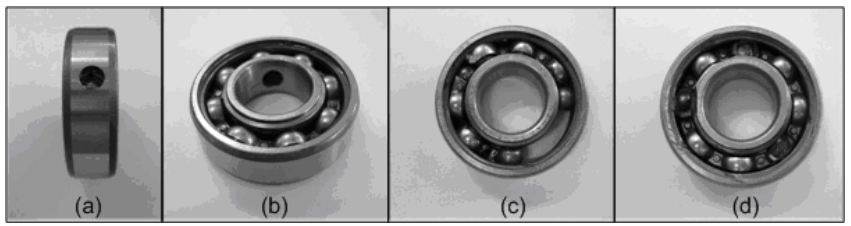

Fig. 12. Artificially deteriorated bearings: (a) outer race deterioration, (b) inner race deterioration, (c) cage deterioration, (d) ball deterioration [22].

TABLE III

VALUES OF THE PROPOSED CRITERION $\sigma^{2}$ FOR HEALTHY AND FAULTY GENERATORS (LOAD $300 \mathrm{~W}$ ).

\begin{tabular}{|l|c|c|}
\hline Generator & $x(n)$ & $y(n)=\mathrm{IMF}_{1}(n)$ \\
\hline Healthy generator & $\sigma^{2}=0.01612$ & $\sigma^{2}=0.00001$ \\
Inner race deterioration & $\sigma^{2}=0.03457$ & $\sigma^{2}=0.00468$ \\
Cage deterioration & $\sigma^{2}=0.03197$ & $\sigma^{2}=0.00210$ \\
Ball deterioration & $\sigma^{2}=0.03324$ & $\sigma^{2}=0.01113$ \\
\hline
\end{tabular}

criterion $\sigma^{2}$ for several generator configurations. Let us denote $x[n]$ the current signal. To highlight the use of the EMD preprocessing, the value of $\sigma^{2}$ is also presented when the amplitude demodulation in (7) is performed on the signal current $x(n)$, directly, instead of on the first IMF $y(n)$. The three tables show that criterion $\sigma^{2}$ is a good generator failure indicator which can be employed to detect several bearing failures (including inner race deterioration, cage deterioration and ball deterioration). Indeed, in each table, $\sigma^{2}$ increases for faulty generators. Furthermore, the experimental results indicate that the proposed method works well under varying load conditions (100W, 200W and 300W). Compared to the direct application of amplitude-demodulation technique, the three tables also show that the use of the first Intrinsic Mode Function makes the failure detection easier. For example in table III, a ball deterioration leads to an increase of $106 \%$ when the amplitude demodulation is performed on $x(n)$ whereas it leads to an increase of $11120 \%$ when it is performed on $y(n)$. This result is not surprising since the stator current signal $x(n)$ is usually multi-components in practice and so the amplitude demodulation cannot be extracted directly from $x(n)$. This explains why $\sigma^{2} \neq 0$ for healthy generator when it is computed from $x(n)$. On the contrary, the EMD preprocessing guarantees that the extracted IMF $y(n)$ is a mono-component signal. Then, this signal can be further processed using an amplitude demodulation technique.

\section{CONCLUSION}

The study reported in this paper focused on the bearing fault detection in DFIG-based wind turbine. Bearing failure is detected using current analysis. First, a mono-component signal is extracted from the stator current signal using an Empirical Mode Decomposition (EMD). Then, the first Intrinsic Mode Function is analyzed through amplitude-demodulation. The experimental results show that the proposed method works well under different conditions and can be applied for the detection of several bearing failures. Moreover, results show that the EMD preprocessing makes the failure detection easier as compared to the direct use of an amplitude demodulation technique.

\section{REFERENCES}

[1] P. Caselitz and M. M. J. Giebhardt, "On-line fault detection and prediction in wind energy converters," in EWEC'94, Thessaloniki, Greece, 1994, pp. 623-627.

[2] — , "Development of a fault detection system for wind energy converters," in EWEC'96, Gteborg, Sweden, 1996, pp. 1004-1007.

[3] — , "Application of condition monitoring systems in wind energy converters," in EWEC'97, Dublin, Ireland, 1997, pp. 579-582.

[4] D. Casadei, F. Filippetti, C. Rossi, A. Stefani, A. Yazidi, and G. Capolino, "Diagnostic technique based on rotor modulating signals signature analysis for doubly fed induction machines in wind generator systems," in IEEE IAS'06, Tampa, USA, 2006.

[5] M. Benbouzid, "A review of induction motors signature analysis as a medium for faults detection," IEEE Transactions on Industrial Electronics, vol. 47, no. 5, pp. 984-993, 2000.

[6] S. Rajagopalan, J. A. Restrepo, J. Aller, T. Habetler, and R. Harley, "Nonstationary motor fault detection using recent quadratic timefrequency representations," IEEE Transactions on Industry Applications, vol. 44, no. 3, 2008.

[7] M. Blodt, D. Bonacci, J. Regnier, M. Chabert, and J. Faucher, "Online monitoring of mechanical faults in variable-speed induction motor drives using the wigner distribution," IEEE Transactions on Industry Applications, vol. 55, no. 2, pp. 522-533, 2008.

[8] M. Blodt, J. Regnier, and J. Faucher, "Distinguishing load torque oscillations and eccentricity faults in induction motors using stator current wigner distributions," IEEE Transactions on Industry Applications, vol. 45, no. 6, pp. 1991-2000, 2009.

[9] J.Cusido, L. Romeral, J. Ortega, J. Rosero, and A. Espinosa, "Fault detection in induction machines using power spectral density in wavelet decomposition," IEEE Transactions on Industrial Electronics, vol. 55, no. 2, pp. 633-643, 2008.

[10] M. Riera-Guasp, J. Antonio-Daviu, J. Roger-Folch, and M. P. M. Palomares, "The use of the wavelet approximation signal as a tool for the diagnosis of rotor bar failure," IEEE Transactions on Industry Applications, vol. 44, no. 3, 2008.

[11] S. Kia, H. Henao, and G. Capolino, "Diagnosis of broken-bar fault in induction machines using discrete wavelet transform without slip estimation," IEEE Transactions on Industry Applications, vol. 45, no. 4, 2009. 
[12] J. R. Stack, R. G. Harley, and T. G. Habetler, "An amplitude modulation detector for fault diagnosis in rolling element bearings," IEEE Transactions on Industrial Electronics, vol. 51, no. 5, 2004.

[13] I. Jaksch, "Fault diagnosis of three-phase induction motors using envelope analysis," in SDEMPED, Atlanta, USA, 2003, pp. 289-293.

[14] B. Trajin, M. Chabert, J. Regnier, and J. Faucher, "Hilbert versus concordia transform for three phase machine stator current time-frequency monitoring," Mechanical systems \& signal processing, vol. 23 , no. 8 , pp. 2648-2657, 2009.

[15] R. Lin, S. Zhu, H. Wu, and J. Zheng, "Rolling bearings fault diagnosis based on energy operator demodulation approach," in 4th World Congress on Intelligent Control and Automation, Shanghai, China, 2002, pp. 2723-2727.

[16] H. Li, L. Fu, and Y. Zhang, "Bearing fault diagnosis based on teager energy operator demodulation technique," in International Conference on Measuring Technology and Mechatronics Automation, Zhangjiajie, China, 2009, pp. 594-597.

[17] N. Huang, Z. Shen, S. Long, M. Wu, H. Shih, Q. Zheng, N. Yen, C. Tung, and H. Liu, "The empirical mode decomposition and hilbert spectrum for nonlinear and nonstationary time series analysis," Proc. Roy. Soc. London, vol. 454, p. 903995, 1998.

[18] D. Yu, J. Cheng, and Y. Yang, "Application of emd method and hilbert spectrum to the fault diagnosis of roller bearings," Mech. Syst. Signal Process., vol. 19, no. 2, 2005.

[19] J. Antonino-Daviu, M. Riera-Guasp, M. Pineda-Sanchez, and R. Prez, "A critical comparison between DWT and Hilbert-Huang-based methods for the diagnosis of rotor bar failures in induction machines," IEEE Transactions on Industry Applications, vol. 45, no. 5, 2009.

[20] G. Rilling, P. Flandrin, and P. Goncalvs, "On empirical mode decomposition and its algorithms," in IEEE-EURASIP Workshop on Nonlinear Signal and Image Processing, Grado, Italia, 2003.

[21] A. Oppenheim, R. Schafer, and W. Padgett, Discrete-Time Signal Processing, 3rd ed. Prentice Hall, 2009.

[22] I. Onel and M. Benbouzid, "Induction motor bearing failure detection and diagnosis: Park and concordia transform approaches comparative study," IEEE/ASME Transactions on mechatronics, vol. 13, no. 2, pp. 257-262, 2008. 